\title{
Tacrolimus, a Calcineurin Inhibitor, Overcomes Treatment Unresponsiveness Mediated by P-glycoprotein on Lymphocytes in Refractory Rheumatoid Arthritis
}

\author{
KATSUNORI SUZUKI, KAZUYOSHI SAITO, SHIZUYO TSUJIMURA, SHINGO NAKAYAMADA, \\ KUNIHIRO YAMAOKA, NORIFUMI SAWAMUKAI, SHIGERU IWATA, MASAO NAWATA, KAZUHISA NAKANO, \\ and YOSHIYA TANAKA
}

\begin{abstract}
Objective. Tacrolimus, a calcineurin inhibitor, is used for treatment of rheumatoid arthritis (RA). It also inhibits functions of P-glycoprotein, which is involved in drug resistance. We examined the mechanisms of early response to 2-week tacrolimus treatment in patients with RA.

Methods. One hundred thirteen patients with refractory RA despite at least 3 antirheumatic agents, including methotrexate, were treated with tacrolimus $(1.5-3 \mathrm{mg} /$ day $)$ and the response was assessed at 2 weeks. Expression of the multidrug resistance $(M D R-1)$ gene and P-glycoprotein was assessed in peripheral blood mononuclear cells (PBMC) collected from 113 patients and 40 healthy subjects. The drug exclusion function by the P-glycoprotein was measured by the residual amount of intracellular tritium-labeled dexamethasone cell/medium ratio ( $\mathrm{C} / \mathrm{M}$ ratio).

Results. The disease activity of enrolled patients was $5.8 \pm 1.2$ (mean \pm SD) by DAS28 erythrocyte sedimentation rate. A good response to tacrolimus was noted at 2 weeks in 22 of 113 patients. At baseline, PBMC of patients with RA showed upregulated expression of $M D R-1$ gene and P-glycoprotein and low $\mathrm{C} / \mathrm{M}$ ratio. The response to tacrolimus correlated with $\mathrm{P}$-glycoprotein expression and $\mathrm{C} / \mathrm{M}$ ratio. A significant improvement in $\mathrm{C} / \mathrm{M}$ ratio was noted after 2 weeks of treatment. The $\mathrm{C} / \mathrm{M}$ ratio correlated significantly with P-glycoprotein expression on CD4+ lymphocytes.

Conclusion. Early efficacy of tacrolimus treatment depended on its inhibitory effect on the drug exclusion function of P-glycoprotein, leading to restoration of intracellular therapeutic levels of corticosteroids and clinical improvement. Evaluation of P-glycoprotein expression on lymphocytes is potentially useful for predicting the response to RA treatment. (First Release Jan 15 2010; J Rheumatol 2010;37:512-20; doi:10.3899/jrheum.090048)
\end{abstract}

\section{Key Indexing Terms: \\ P-GLYCOPROTEIN TACROLIMUS}

RHEUMATOID ARTHRITIS

\section{DRUG RESISTANCE CALCINEURIN INHIBITOR}

Rheumatoid arthritis (RA) is a systemic disease characterized pathologically by the presence of autoreactive lymphocytes and clinically by tenderness and swelling of multiple joints. Treatment of RA includes the use of antirheumatic

From the First Department of Internal Medicine, University of Occupational and Environmental Health, Japan.

Supported in part by Grants-In-Aid for scientific research from the Ministry of Health, Labor and Welfare of Japan; the Ministry of

Education, Culture, Sports, Science and Technology of Japan; and the

University of Occupational and Environmental Health, Japan.

K. Suzuki, MD; K. Saito, MD, PhD; S. Tsujimura, MD, PhD;

S. Nakayamada, MD, PhD; K. Yamaoka, MD, PhD; N. Sawamukai, MD, PhD; S. Iwata, MD; M. Nawata, MD; K. Nakano, MD, PhD; Y. Tanaka, $M D, P h D$.

Address correspondence to Dr. Y. Tanaka, First Department of Internal Medicine, University of Occupational and Environmental Health, Japan, 1-1 Iseigaoka Yahatanishi Kitakyushu 807-8555, Japan.

E-mail:tanaka@med.uoeh-u.ac.jp

Full Release Article. For details see Reprints/Permissions at jrheum.org Accepted for publication October 14, 2009. drugs designed to correct the autoreactive lymphocytes ${ }^{1}$. However, some patients respond poorly to such $\operatorname{drugs}^{2}$ or develop resistance to them after an initial response ${ }^{3}$.

Drug resistance is partly caused by disturbance of the drug exclusion pump of P-glycoprotein on the surface of tumor cells $\mathrm{s}^{4-8}$. P-glycoprotein is induced by transcription factor YB-1, which is activated by various external stimuli such as drugs and inflammatory cytokines and is expressed on cells following the induction of multidrug resistance gene $(M D R-1)$.

We have reported the expression of P-glycoprotein in lymphocytes and that its expression pathway is similar to that of drug exclusion ${ }^{9}$. The transcription factor YB-1 is expressed in the cytoplasm of peripheral blood lymphocytes of healthy subjects ${ }^{9}$. Absence of $M D R-1$ gene expression is associated with weak or no P-glycoprotein expression ${ }^{9}$. Thus, in peripheral blood lymphocytes of patients with RA, stimuli from inflammatory cytokines, such as interleukin 2 
(IL-2), and stimuli from cells injured by longterm exposure to antiinflammatory drugs and corticosteroids, cause translocation of transcription factor YB-1 from the cytoplasm into the nucleus, which in turn triggers the expression of $M D R-1$. Further, P-glycoprotein is expressed on the surface of lymphocytes, and drugs that are substrates of P-glycoprotein are exported outside the cell ${ }^{9}$.

Similar to cyclosporine, tacrolimus is an effective drug widely used as a calcineurin inhibitor, particularly in transplant surgery ${ }^{10,11}$. Intracellularly, tacrolimus forms a complex with FK binding protein (FKBP-12). The complex binds to calcineurin, which results in inhibition of its activation. The complex also inhibits the activation of the transcription factor nuclear factor-ATc, thus preventing its entry into the nucleus. Consequently, the transcription of cytokines such as IL-2 and IL-4 is blocked, resulting in suppression of RA disease ${ }^{12-15}$. We reported previously that cyclosporine, a calcineurin inhibitor, also inhibits P-glycoprotein, and it can thus eliminate drug resistance in systemic lupus erythematosus, which is caused by drug exclusion due to expression of P-glycoprotein ${ }^{9,16}$.

Tacrolimus also inhibits P-glycoprotein ${ }^{17,18}$; however, the drug resistance blocking action of tacrolimus is still unexplained, as is the consequence of this on treatment of RA. Studies indicate that the clinical effects of tacrolimus on RA appear after 1-2 months of treatment ${ }^{19-25}$. In our study, we report rapid improvement in clinical symptoms and laboratory tests after 2-week treatment with tacrolimus. Based on this finding, we then investigated the clinical effects of tacrolimus combined with other drugs including corticosteroids, which are substrates of P-glycoprotein. The results showed that tacrolimus suppresses drug exclusion by inhibiting P-glycoprotein, thus allowing restoration of therapeutic levels of corticosteroids within the cells.

\section{MATERIALS AND METHODS}

Patients. The subjects were 113 patients with RA who met the diagnostic criteria of the American College of Rheumatology ${ }^{26}$ and showed resistance to antirheumatic agents. In addition, the study included peripheral blood samples from 40 healthy adults, matched by age and sex to the patients with RA. The control subjects were either staff members of our hospital or healthy subjects who visited our hospital for medical examinations. Patients with RA that was resistant to treatment were defined as patients with a Disease Activity Score (DAS28) erythrocyte sedimentation rate (ESR) score $>3.1$ for RA activity despite receiving treatment with adequate doses of at least 3 antirheumatic drugs, including methotrexate (MTX), for a minimum of 3 months, and showing no or moderate response, according to the European League Against Rheumatism (EULAR) improvement criteria $^{27-29}$. Tacrolimus was used for these patients with treatment-resistant RA. Tacrolimus was administered at a daily dose of $3 \mathrm{mg}$ in patients $\leq 65$ years of age and $1.5 \mathrm{mg}$ for those aged $\geq 65$ years. All other antirheumatic drugs used by the enrolled patients were withheld during our 4-week study, except for nonsteroidal antiinflammatory drugs and corticosteroids. One patient who underwent treatment by biological disease-modifying antirheumatic drugs was not included in our study.

We started tacrolimus at the hospital of the University of Occupational and Environmental Health, Japan. The same person evaluated the clinical efficacy of tacrolimus throughout the observation period. The expression of
P-glycoprotein on lymphocytes and polymerase chain reaction (PCR) analysis of the MDR-1 gene were conducted by an individual different from the one who evaluated the clinical effects such as the number of swollen and tender joints, and evaluation by visual analog scale. Data analysis was performed by a third individual blinded to the other 2 investigators.

The Human Ethics Review Committee of the university reviewed and approved our study, including the collection of peripheral blood samples from healthy adults and patients with RA. Each subject provided a signed participation consent form.

Measurements. The background factors investigated were sex, age, duration of RA, dosage of antirheumatic drugs including corticosteroids, history of treatment, use of concomitant drugs such as corticosteroids at the time of initiation of tacrolimus therapy, and the dosage of other drugs.

We also evaluated the severity of morning stiffness, number of swollen joints, number of tender joints, and patient-evaluated pain and overall evaluation by a visual analog scale, in addition to evaluation by the attending physician. The response to treatment was evaluated using the EULAR criteria ${ }^{28,30,31}$. The laboratory tests included C-reactive protein (CRP), ESR, rheumatoid factor (RF), and matrix metalloproteinase-3.

Expression of P-glycoprotein on peripheral blood mononuclear cells. Peripheral blood mononuclear cells (PBMC) were separated by specific gravity fractionation using Lymphocyte Separation Medium 50494 (Pharmacia Biotech, Uppsala, Sweden). Of the CD antigens that were expressed on PBMC, $\geq 90 \%$ were on lymphocytes (CD4, CD8-, or CD19+ cells) and $\leq 10 \%$ were on mononuclear cells. PBMC were stained and analyzed by flow cytometry using the standard procedure of FACScan (Becton Dickinson, Mountain View, CA, USA) as described ${ }^{32,33}$. The cells were divided to a final concentration of $2 \times 10^{5}$ cells/well. Polyclonal $\gamma$-globulin (10 $\mu \mathrm{g} / \mathrm{ml}$; Mitsubishi Welpharma Co., Osaka, Japan) was added to the culture to block Fc receptors. After culture, MRK-16 (100 $\mu \mathrm{g} / \mathrm{ml}$; Kyowa Medex, Tokyo, Japan), a monoclonal antibody specific for P-glycoprotein $^{34}$, was added to the culture solution. The cells were further labeled with FITC-conjugated antimouse IgG antibody $(5 \mu \mathrm{g} / \mathrm{ml}$; Fujisawa, Osaka, Japan). For cell staining, cells were treated with antimouse $\mathrm{IgG}$ that binds to nonspecific sites before using phycoerythrin-conjugated $\mathrm{CD} 4 \mathrm{mAb}$ or $\mathrm{CD} 19 \mathrm{mAb}(1.25 \mu \mathrm{g} / \mathrm{ml}$; Becton Dickinson). Of these double-stained cells, target cells that were gated based on CD4 or CD19 expression were extracted using FACScan. Quantification of the cell surface antigens on 1 cell was performed using QIFIKIT beads (Dako, Kyoto, Japan) as reported ${ }^{33,35}$. The data were used to construct a calibration curve of the mean fluorescence intensity versus antibody-binding capacity. The cell specimen was analyzed on the FACScan and the antibody-binding capacity calculated by interpolation on the calibration curve. When the green-fluorescence laser detection was set at $500 \mathrm{~nm}$ in the FACScan, the antibody-binding capacity was equal to $202.98 \times \exp (0.0092 \times$ mean fluorescence intensity $)\left(R^{2}=0.9995\right)$. Subsequently, the specific antibody-binding capacity was obtained after correcting for the background and apparent antibody-binding capacity of the negative control antimouse IgG antibody. The specific antibody-binding capacity represented the mean number of accessible antigenic sites per cell, referred to as antigen density and expressed in sites/cell.

Cell/medium ratio (C/M ratio) of dexamethasone. To assess the function of P-glycoprotein, PBMC were collected from patients with RA and analyzed for the residual amounts of carbon-labeled butanol and tritium-labeled dexamethasone in cells. The C/M ratio represented the coefficient of intracellular and extracellular ratio of dexamethasone and was determined using the formula:

$\mathrm{C} / \mathrm{M}$ ratio $=\left[\left({ }^{3} \mathrm{H}\right.\right.$ in cell fraction $/{ }^{14} \mathrm{C}$ in cell fraction $) /$ $\left({ }^{3} \mathrm{H}\right.$ in medium fraction $/{ }^{14} \mathrm{C}$ in medium fraction)]

Changes in the residual amount of the drug in PBMC of patients with RA were assessed by pretreatment of the cells with tacrolimus $0-50 \mathrm{ng} / \mathrm{ml}$, sulfasalazine (SSZ) 0-50 $\mu \mathrm{g} / \mathrm{ml}$, or MTX 0-400 ng/ml.

Carbon-labeled n-butanol (1.61 mCi/mmol; Toho Biomedical, Tokyo, 
Japan) was diluted with $0.5 \mathrm{MBq} / \mathrm{ml}$ of non-carbon-labeled butanol (Sigma Aldrich, Tokyo, Japan). Tritium-labeled dexamethasone $(40.0 \mathrm{Ci} / \mathrm{mmol}$; Perkin Elmer, Boston, MA, USA) was dissolved in dimethyl sulfoxide (DMSO; Nacalai Tesque Inc., Tokyo, Japan) and diluted with phosphatebuffered saline (PBS; adjusted to a final concentration of DMSO of $0.1 \%$ ). To supply ATP, $7 \mathrm{mM}$ of dextrose was added to PBS. PBMC were suspended in this solution and adjusted so that the cell density was $5 \times 10^{6}$ cells $/ \mathrm{ml}^{36}$. PBMC were cultured at $37^{\circ} \mathrm{C}$ for $20 \mathrm{~min}$ in $5 \times 10^{-5} \mathrm{M}$ of carbon-labeled butanol and $3.0 \times 10^{-8} \mathrm{M}$ of tritium-labeled dexamethasone. After the culture, $100 \mu 1$ aliquots of the cells were layered in $80 \mu 1$ of a mixture of lauryl bromide and silicone oil (2:1 ratio; Nacalai Tesque) in an Eppendorf tube (Assist, Tokyo, Japan). After centrifugation at 10,000 rpm for $2 \mathrm{~min}$, the tube was instantly frozen in liquid nitrogen. The frozen tube was divided into medium (upper layer) and mixture (cell components, bottom layer) bound parts. Soluene-350 and $10 \mathrm{ml}$ Hionic-Flouor (Packard, Meriden, CT, USA) were added to the cell components. The medium part was dissolved in a mixture of toluene (Wako Pure Chemicals, Osaka, Japan), methanol (Wako), ethylene glycol monoethanol (Nacalai Tesque), and Permaflour (ratio 200:50:50:12; Packard). Both parts were irradiated using a scintillation counter

Reverse transcription-PCR. Whole-cell RNA was obtained from PBMC of healthy adults and patients with RA and separated using the Isogen (Wako) protocol. Total RNA (500 ng) was reverse transcribed for $30 \mathrm{~min}$ at $42^{\circ} \mathrm{C}$. Denaturing was performed for $45 \mathrm{~s}$ using iCycler (Bio-Rad, Richmond, CA, USA). Amplification was performed with annealing at $55^{\circ} \mathrm{C}$ for $45 \mathrm{~s}$ and extension at $72^{\circ} \mathrm{C}$ for $90 \mathrm{~s}$ using the 30-cycle specific $M D R-1$ and $B$-actin primers. The sequences of the primers are human $B$-actin forward, 5'-TGA ACC CCA AGG CCA ACC GC-3', reverse, 5'-TTG TGC TGG GTG CCA GGG CA-3'; and human MDR-1 forward, 5'-CCC ATC ATT GCA ATA GCA GG-3', reverse, 5'-GTT CAA ACT TCT GCT CCT GA-3'. Amplified products were electrophoresed with Marker 4 (Nippon Gene, Tokyo, Japan) on 3\% agarose gels.

Statistical analysis. Continuous variables related to patients' background are presented as mean \pm standard deviation. Differences between 2 groups were tested statistically by Wilcoxon test.

Correlations between background factors and response to treatment at Week 2 were analyzed by Pearson's correlation coefficient. Multivariate logistic analysis was also performed. A 2-tailed $p$ value $\leq 0.05$ was considered statistically significant. All statistical analyses were performed using JMP software, version 7.0 (SAS Institute Inc, Cary, NC, USA) on Mac OSX.

\section{RESULTS}

A total of 113 patients with RA were treated with tacrolimus. The mean age of the population was $65.5 \pm 12.2$ years (median 66 yrs), mean disease duration was $114 \pm 120$ months (median $96 \mathrm{mo}$ ), the ratio of men to women was 23:90, the mean dose of corticosteroid was $2.69 \pm 3.69$ $\mathrm{mg} / \mathrm{day}$, and the rate of concomitant treatment with corticosteroid was $56 \%$.

The mean DAS28-ESR of the enrolled patients with RA at the time of initiation of tacrolimus treatment was $5.8 \pm 1.2$ (median 5.9) and the percentage of patients with a high DAS28-ESR disease activity score $(\geq 5.1)$ was $83 \%$ (Figure 1A). However, the percentage of patients with a DAS28-ESR disease activity score $<3.2$, categorized as low disease activity, increased from $0 \%$ at baseline to $23 \%$ after 2 weeks of the tacrolimus therapy. The percentages of patients with a good response, moderate response, and no response were $19 \%, 34 \%$, and $47 \%$, respectively, according to the improve- ment criteria for response to treatment proposed by the EULAR (Figure 1B). In general, the clinical efficacy of tacrolimus, mediated through inhibition of calcineurin, becomes evident after more than 1 month of therapy. However, in our study, about $20 \%$ of the patients showed marked response at 2 weeks after the start of treatment. The effects lasted for 12 weeks after tacrolimus treatment and DAS28 gradually decreased, and the proportion of patients who achieved more than moderate response also increased.

Next, we investigated the mechanism of the marked response to 2 -week tacrolimus treatment. To examine the possibility that the early efficacy was due to the inhibitory effect of tacrolimus on P-glycoprotein, we analyzed P-glycoprotein expression on lymphocytes and drug exclusion by $\mathrm{P}$-glycoprotein using the $\mathrm{C} / \mathrm{M}$ ratio. $\mathrm{P}$-glycoprotein was overexpressed in CD4 and CD19 lymphocytes of patients with RA, compared with the healthy controls (Figure 2A). The $M D R-1$ gene was not expressed in the lymphocytes of healthy controls. In contrast, even with no stimulation, the MDR-1 gene was clearly expressed (Figure 2B) in lymphocytes of all of 5 representative patients with RA (patients 1-3 had good response and 4 and 5 had moderate response).

We also measured intracellular concentrations of tritium-labeled dexamethasone in vitro. In healthy adult lymphocytes that do not express $\mathrm{P}$-glycoprotein, the $\mathrm{C} / \mathrm{M}$ ratio increased in a time-dependent manner. In contrast, there was no increase in $\mathrm{C} / \mathrm{M}$ ratio in $\mathrm{P}$-glycoprotein-expressing lymphocytes of patients with RA (Figure 3A). The addition of tacrolimus at 0-50 ng/ml, which has an inhibitory effect on $\mathrm{P}$-glycoprotein, increased the $\mathrm{C} / \mathrm{M}$ ratio in a dose-dependent manner (Figure 3B). However, the addition of MTX or SSZ as the control drug did not result in any significant change in the $\mathrm{C} / \mathrm{M}$ ratio (Figure $3 \mathrm{~B}$ ).

Next, we analyzed the relationships among various background factors and the response to tacrolimus treatment (Table 1). The response to such treatment was not influenced by factors related to RA disease activity, including number of swollen joints, number of tender joints, visual analog scale, CRP, and ESR. Further, the response to tacrolimus treatment did not correlate with age, sex, duration of illness, mean corticosteroid dose, and tacrolimus dose. On the other hand, the rate of concomitant use of corticosteroids was significantly different among nonresponders $(32 / 53 ; 60.4 \%)$, moderate responders $(18 / 38 ; 47.4 \%)$, and good responders $(22 / 22 ; 100 \%)$, as shown in Table 1. The percentage of patients using corticosteroids who did not achieve good response to tacrolimus (53.9\%) was significantly lower than that of patients who did.

We also analyzed the correlation between response to treatment and $\mathrm{P}$-glycoprotein expression and $\mathrm{C} / \mathrm{M}$ ratio (Table 1). In this analysis, P-glycoprotein expression on CD4- and CD19+ lymphocytes was stratified by the response to treatment. The expression levels of P-glycoprotein in both CD4- and CD19+ lymphocytes were signifi- 
(a)

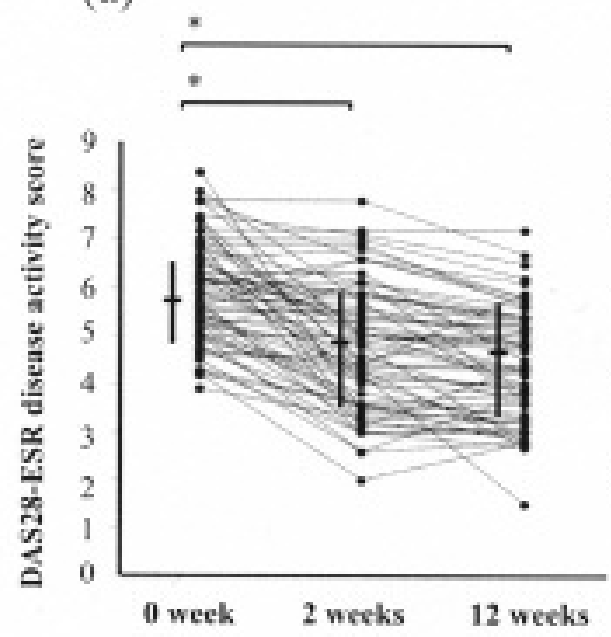

(b)
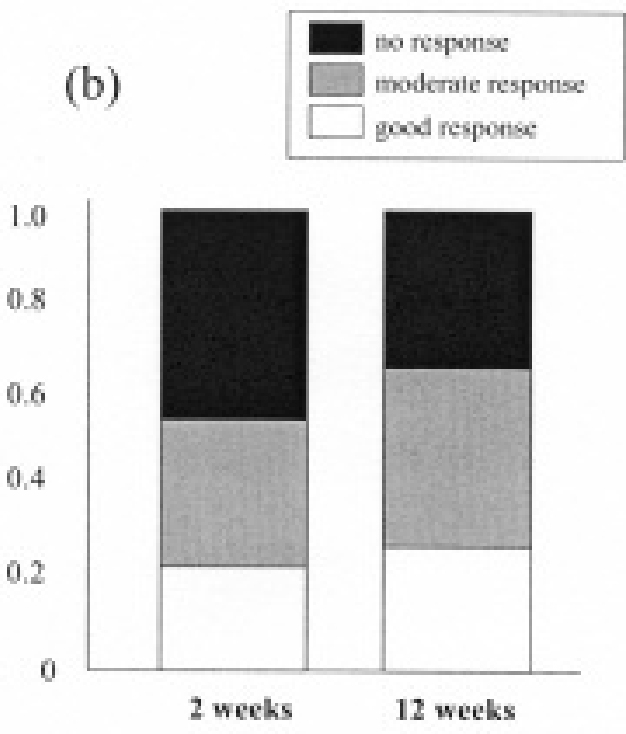

Figure 1. Changes in disease activity and treatment response at baseline (before induction of tacrolimus treatment) and at 2 and 12 weeks of treatment in patients with treatment-resistant RA. RA disease activity was assessed by DAS28-ESR. Treatment response was assessed using EULAR criteria. A. Disease activity. Data for individual patients and mean $\pm \mathrm{SD}$ values for baseline and posttreatment for the groups. $* \mathrm{p}<0.05$, Wilcoxon test. B. Treatment response at 2 and 12 weeks after commencement of tacrolimus treatment.

\section{(a)}

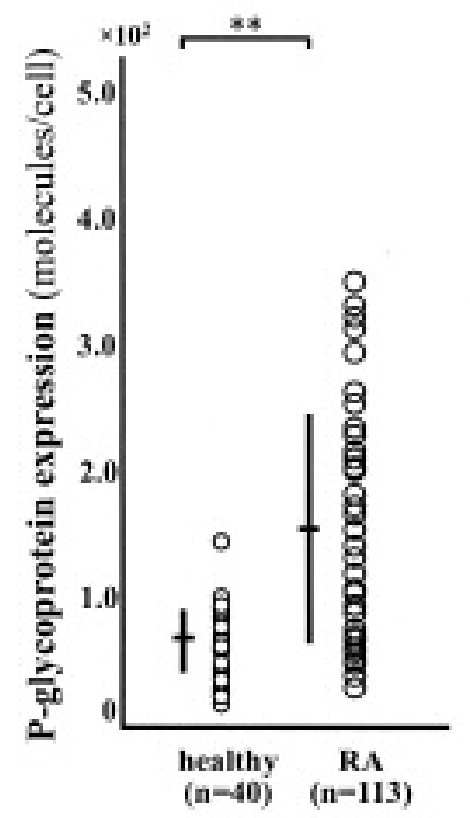

CD4-positive lymphocytes

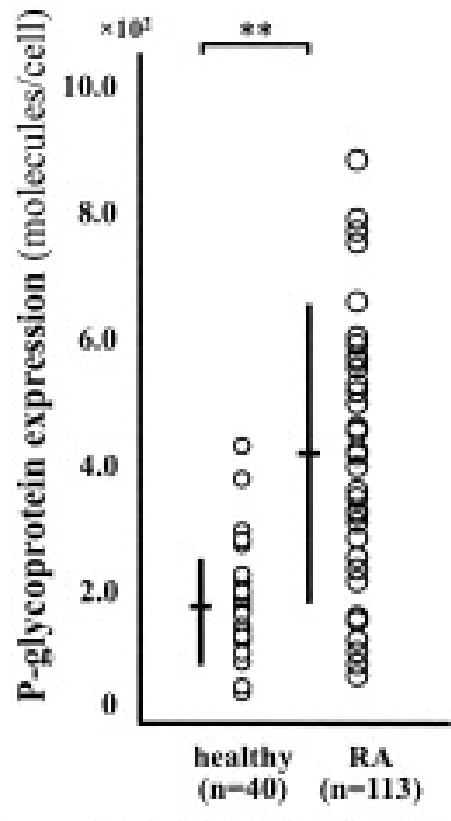

CD19-positive lymphocytes

(b)

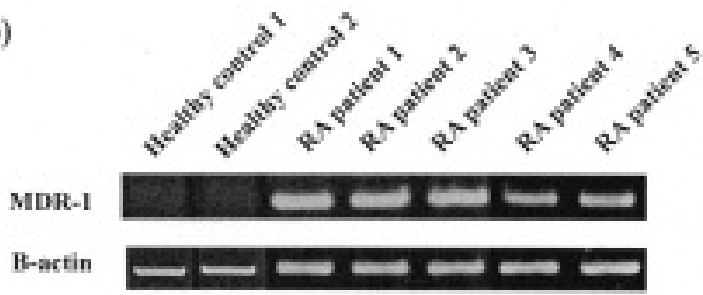

Figure 2. P-glycoprotein expression on lymphocytes of patients with RA treated with tacrolimus and healthy controls. A. Mononuclear cells were isolated from peripheral blood of patients with treatment-resistant RA and controls and stained with CD4 and CD19 antibodies and P-glycoprotein antibodies. Expression of P-glycoprotein on lymphocyte was measured. Data for individual subjects and mean \pm SD values of the 2 groups are shown. $* * \mathrm{p}<0.01$, Wilcoxon test. B. Multidrug resistance gene $(M D R-1)$ was assessed by RT-PCR. Note the expression of $M D R-1$ in patients with treatment-resistant RA but not in healthy controls. Representative results of 5 experiments with similar results. Electrophoresis was performed on the amplifier together with Marker 4 in $3 \%$ agarose gel. 
(a)
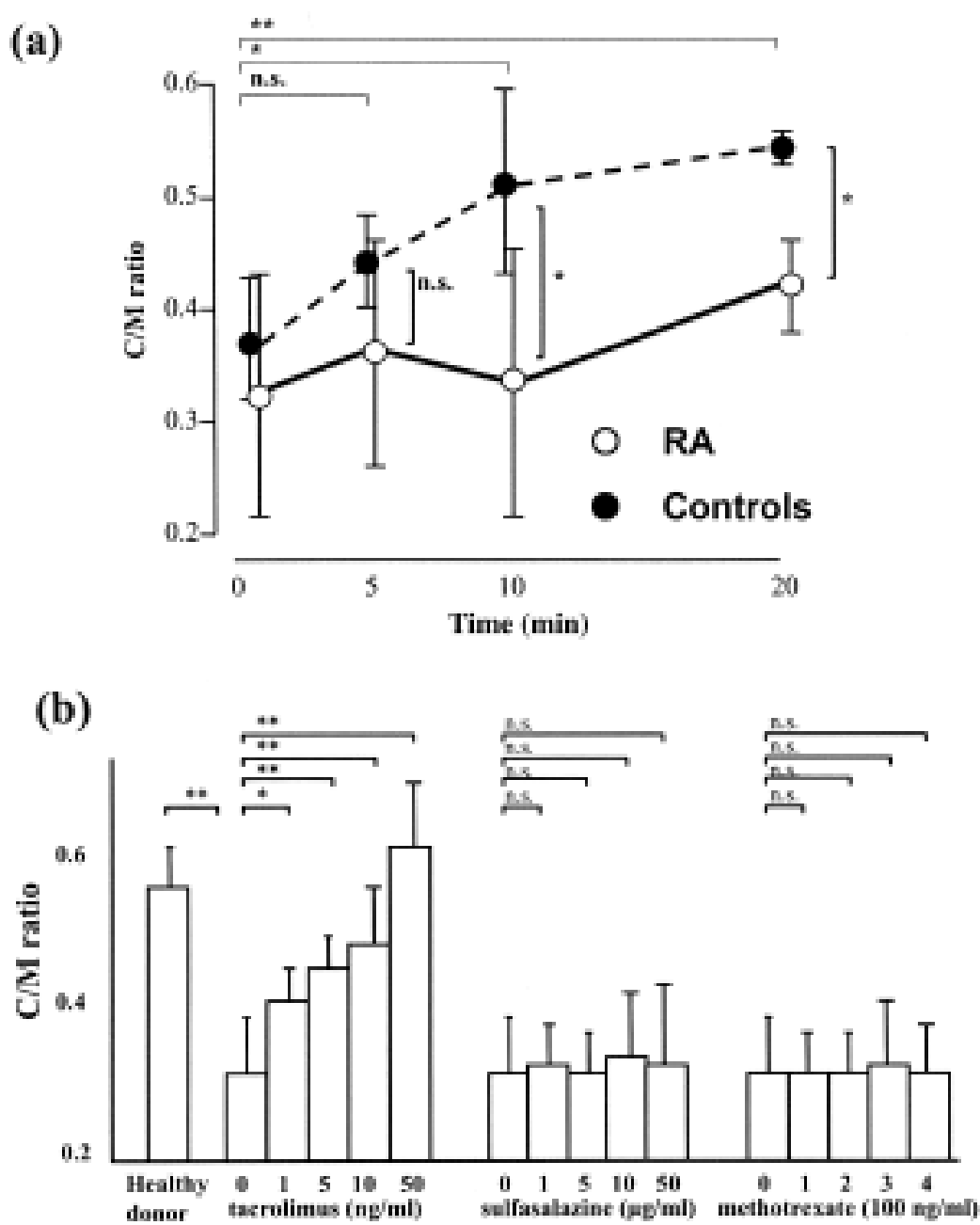

Figure 3. Serial changes in cell/medium $(\mathrm{C} / \mathrm{M})$ ratio and changes in $\mathrm{C} / \mathrm{M}$ ratio after the addition of drugs. Data are mean \pm SD. A. Serial changes in C/M ratio. B. Changes in C/M ratio of peripheral blood mononuclear cells from patients with treatment-resistant RA in response to tacrolimus and 2 anti-RA drugs, sulfasalazine and methotrexate. ${ }^{*} \mathrm{p}<0.05$, $* * p<0.01$, Wilcoxon test; ns: nonsignificant.

cantly higher in the good response group compared with the other groups (no response and moderate response; Table 1, Figure 4A). Moreover, the $\mathrm{C} / \mathrm{M}$ ratio was significantly lower in the good response group compared with the moderate or no response group. Interestingly, the $\mathrm{C} / \mathrm{M}$ ratio before the initiation of tacrolimus treatment was significantly lower in the good response group compared with the moderate and no response groups (Figure 4B). However, at 2 weeks after the initiation of tacrolimus treatment, the value improved significantly in the good response group compared with the moderate and no response groups (Figure 4C). In addition, P-glycoprotein expression at 2 weeks after initiation of tacrolimus therapy was similar to that at baseline (before therapy; Figure 4D).

Finally, multivariate logistic regression analysis was used to determine those factors that can explain the response to tacrolimus treatment. The analysis included the $\mathrm{C} / \mathrm{M}$ ratio, $\mathrm{P}$-glycoprotein expression on $\mathrm{CD} 4+$ lymphocytes, CRP, and morning stiffness. Multivariate logistic regression analysis identified the $\mathrm{C} / \mathrm{M}$ ratio and $\mathrm{P}$-glycoprotein expression on CD4+ lymphocytes as significant and independent determinants of a good response to tacrolimus treatment (Table 2).

\section{DISCUSSION}

The safety and efficacy of tacrolimus in the treatment of RA is currently under investigation. The response of patients with RA to tacrolimus treatment is normally investigated about 1-2 months after initiation of such treatment ${ }^{19-25}$. In our study, however, we noted that some patients responded 
Table 1. Baseline clinical characteristics of patients with RA treated with tacrolimus. P value represents differences between good response and moderate and no response groups.

\begin{tabular}{|c|c|c|c|c|}
\hline Characteristics & $\begin{array}{l}\text { No Response } \\
\quad(n=53)\end{array}$ & $\begin{array}{l}\text { Moderate Response } \\
\qquad(\mathrm{n}=38)\end{array}$ & $\begin{array}{l}\text { Good Response } \\
\qquad(\mathrm{n}=22)\end{array}$ & $\mathrm{p}$ \\
\hline Age (yrs) & $65.1 \pm 12.7$ & $66.2 \pm 15.3$ & $68.0 \pm 12.2$ & NS \\
\hline Disease duration (mo) & $166 \pm 143$ & $115 \pm 108$ & $171 \pm 157$ & NS \\
\hline Morning stiffness (min) & $278 \pm 369$ & $171 \pm 323$ & $195 \pm 413$ & NS \\
\hline No. of tender joints & $10.2 \pm 6.1$ & $8.6 \pm 4.6$ & $9.9 \pm 8.2$ & NS \\
\hline No. of swollen joints & $9.0 \pm 4.3$ & $7.3 \pm 4.8$ & $7.0 \pm 3.9$ & NS \\
\hline Visual analog scale (mm) & $56.5 \pm 18.6$ & $66.5 \pm 21.0$ & $54.6 \pm 24.5$ & NS \\
\hline C-reactive protein (mg/dl) & $2.8 \pm 2.6$ & $1.5 \pm 1.6$ & $2.2 \pm 2.6$ & NS \\
\hline Erythrocyte sedimentation rate (ESR, mm/h) & $60 \pm 29$ & $48 \pm 26$ & $42 \pm 32$ & NS \\
\hline Rheumatoid factor (IU/I) & $275 \pm 341$ & $423 \pm 1103$ & $68 \pm 63$ & NS \\
\hline Matrix metalloproteinase & $296 \pm 302$ & $302 \pm 371$ & $192 \pm 139$ & NS \\
\hline Disease activity 28 ESR & $5.8 \pm 0.7$ & $5.7 \pm 0.8$ & $5.3 \pm 0.9$ & NS \\
\hline Prednisone (mg) & $1.3 \pm 2.6$ & $1.5 \pm 3.8$ & $2.9 \pm 2.7$ & NS \\
\hline Patients on prednisone (\%) & $60.4(32 / 53)$ & $47.4(18 / 38)$ & $100(22 / 22)$ & 0.05 \\
\hline Tacrolimus (mg) & $2.1 \pm 0.8$ & $2.0 \pm 0.8$ & $1.9 \pm 0.8$ & NS \\
\hline P-glycoprotein expression on CD4 (molecule/cell) & $140 \pm 58$ & $159 \pm 65$ & $248 \pm 110$ & 0.05 \\
\hline P-glycoprotein expression on CD19 (molecule/cell) & $374 \pm 171$ & $388 \pm 173$ & $586 \pm 193$ & 0.05 \\
\hline $\mathrm{C} / \mathrm{M}$ ratio & $0.49 \pm 0.12$ & $0.49 \pm 0.17$ & $0.36 \pm 0.12$ & 0.01 \\
\hline
\end{tabular}

C/M: cell/medium. NS: nonsignificant.

markedly well to tacrolimus treatment after only 2 weeks. In order to explain this early response to treatment, we investigated the inhibitory effect of tacrolimus on P-glycoprotein, both in vitro and in vivo. PBMC of patients with RA showed expression of the MDR-1 gene, and overexpression of P-glycoprotein on the lymphocyte surface. These features were not identified in PBMC from healthy adults. Further, the $\mathrm{C} / \mathrm{M}$ ratio in patients with $\mathrm{RA}$ was lower than that of the healthy adults, indicating enhanced drug exclusion function of P-glycoprotein. However, in in vitro experiments, the addition of tacrolimus to PBMC improved the $\mathrm{C} / \mathrm{M}$ ratio to a level similar to that of healthy adults, and the response depended on the dose of tacrolimus added to the cell culture. We also tested the response of PBMC to $0-50 \mathrm{~g} / \mathrm{ml} \mathrm{SSZ}$ and 0-400 ng/ml MTX. These doses represent the $C_{\max }$ values used clinically. At these concentrations, SSZ and MTX, which do not inhibit P-glycoprotein, did not improve the $\mathrm{C} / \mathrm{M}$ ratio. These findings indicate that the improvement in $\mathrm{C} / \mathrm{M}$ ratio is not due to a secondary inhibition of P-glycoprotein through inhibition of lymphocyte activation. The results of in vitro experiments were confirmed in vivo; tacrolimus produced a significant increase in the $\mathrm{C} / \mathrm{M}$ ratio of patients who showed a good response to 2-week tacrolimus therapy (based on the improvement criteria of EULAR). Multivariate logistic analysis indicated that after 2 weeks of tacrolimus treatment, overexpression of P-glycoprotein on lymphocytes in the good response group correlated significantly with a low $\mathrm{C} / \mathrm{M}$ ratio before treatment. Since all patients were also treated with corticosteroids throughout the study, the above findings suggest that the early response to tacrolimus therapy was not due to tacrolimus alone but also to inhibition of extracellular exclusion of corticosteroids, mediated by the inhibitory effect of tacrolimus on P-glycoprotein expression. In addition, there were no differences in P-glycoprotein expression between initiation and 2 weeks after initiation of tacrolimus (Figure 4D). Therefore, the main effect of tacrolimus was due, not to a decrease in P-glycoprotein molecules on lymphocytes, but to functional competitive inhibition of drug exclusion.

Humoral factors such as TNF- $\alpha$, IL-6, and IL-1 that are locally produced in joints, or upregulation of P-glycoprotein expression through induction of transcription of $M D R-1$ gene following activation of YB-1 by certain drugs that are added to the treatment for RA such as antirheumatic drugs and corticosteroids, are involved in the development of resistance to treatment in patients with RA. Often, the same drug must be used continuously over a long period to control RA disease activity. During this period, expression of the multidrug resistance genes may be induced due to increased disease activity, resulting in drug resistance. For example, increased disease activity and low response rate following longterm use have been reported during treatment with SSZ. In fact, upregulation of P-glycoprotein expression was reported in low responders to SSZ ${ }^{37}$. With SSZ, which is used in the treatment of RA, stimulation of cells that enhance P-glycoprotein expression causes simultaneous extracellular exclusion of the drug. Thus, the low response to SSZ is probably due to increased extracellular exclusion of the drug through P-glycoprotein. The above finding of the inhibitory effect of tacrolimus on P-glycoprotein expression suggests that tacrolimus could potentially improve the resistance to other drugs in addition to corticosteroids.

We demonstrated that tacrolimus inhibits drug exclusion mechanisms operating through P-glycoprotein in patients with good response after 2 weeks of treatment. As a drug used for management of treatment-resistant RA, tacrolimus 

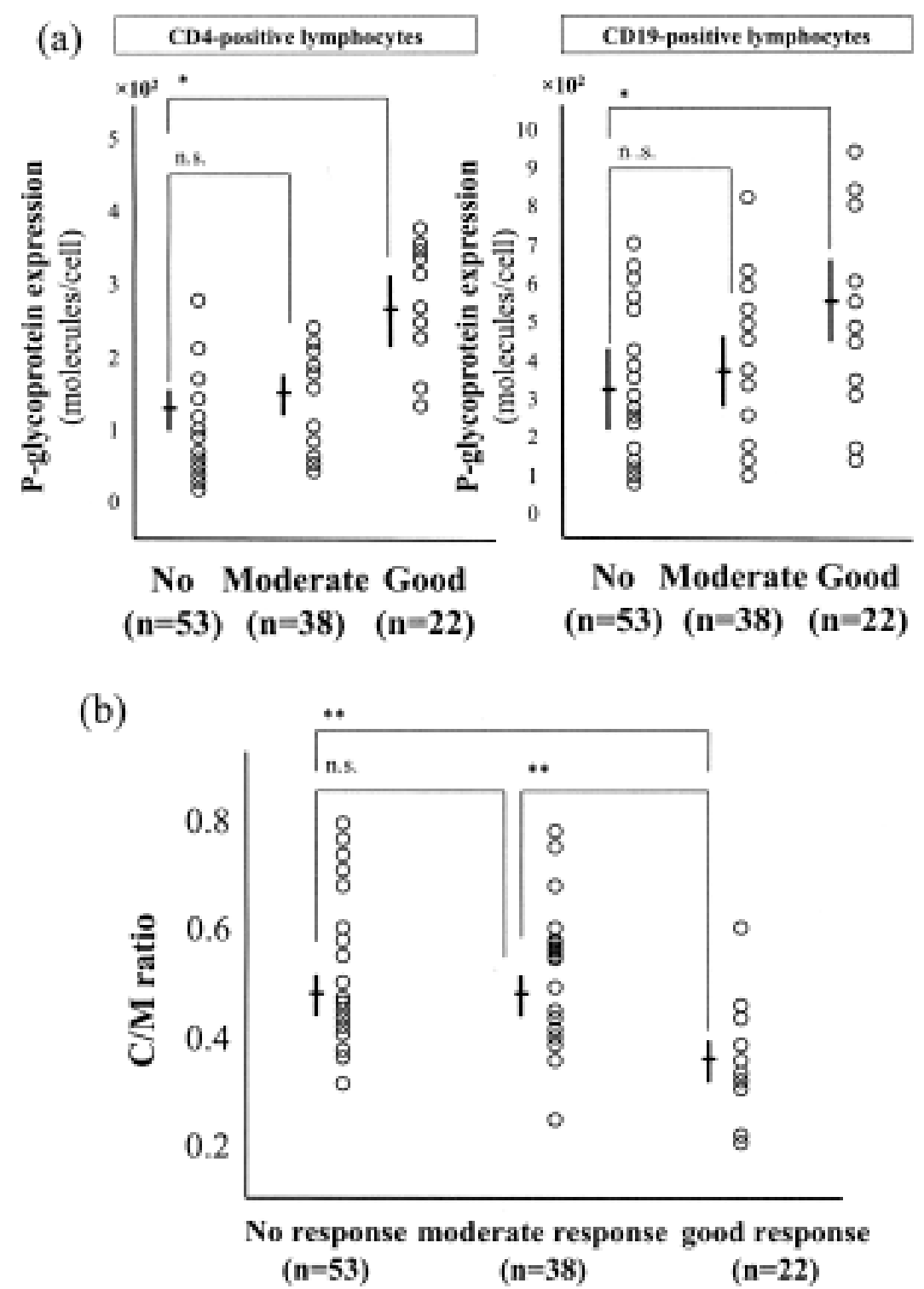

Figure 4. Responses to 2-week treatment with tacrolimus. Data represent values of individual patients and group mean \pm SD values. A. Expression of P-glycoprotein on CD4 and CD19 lymphocytes of patients with treatment-resistant RA. B. C/M ratio of peripheral blood mononuclear cells (PBMC) from patients with treatment-resistant RA. C. C/M ratio measured in PBMC of patients with RA before and after 2-week tacrolimus treatment. D. Expression of P-glycoprotein on CD4 lymphocytes of patients with RA before and after 2-week tacrolimus treatment. ${ }^{*} \mathrm{p}<0.05, * * \mathrm{p}<0.01$, Wilcoxon test; ns: nonsignificant.

inhibits disease activity by blocking the calcineurin pathway and improves the low response by inhibiting drug exclusion of concomitantly used drugs through P-glycoprotein. Thus, among the existing antirheumatic drugs, tacrolimus is a potentially useful drug, although its mechanism of action is unknown. Patients on combination treatment have high expression levels of $\mathrm{P}$-glycoprotein and low $\mathrm{C} / \mathrm{M}$ ratio before the initiation of tacrolimus treatment because the concomitantly used drug, such as a corticosteroid, becomes a substrate for P-glycoprotein. Thus, in such patients, treatment with tacrolimus is expected to result in an increase in intracellular concentration of corticosteroids through the inhibitory effect of tacrolimus on P-glycoprotein, leading to a rapid remanifestation of the clinical efficacy of corticosteroid and thus early efficacy. In other words, it is likely that tacrolimus, through its inhibitory action on P-glycoprotein, can lower treatment resistance due to extracellular exclusion of drugs such as corticosteroids and SSZ, leading to improved response to treatment. Our results suggest that initiation of tacrolimus treatment for such patients is highly useful clinically. In addition, the determination of P-glycoprotein expression level on lymphocytes, which correlates with clinical response, is useful for predicting the response to treatment as well as helping with the choice of therapy. 
(c)

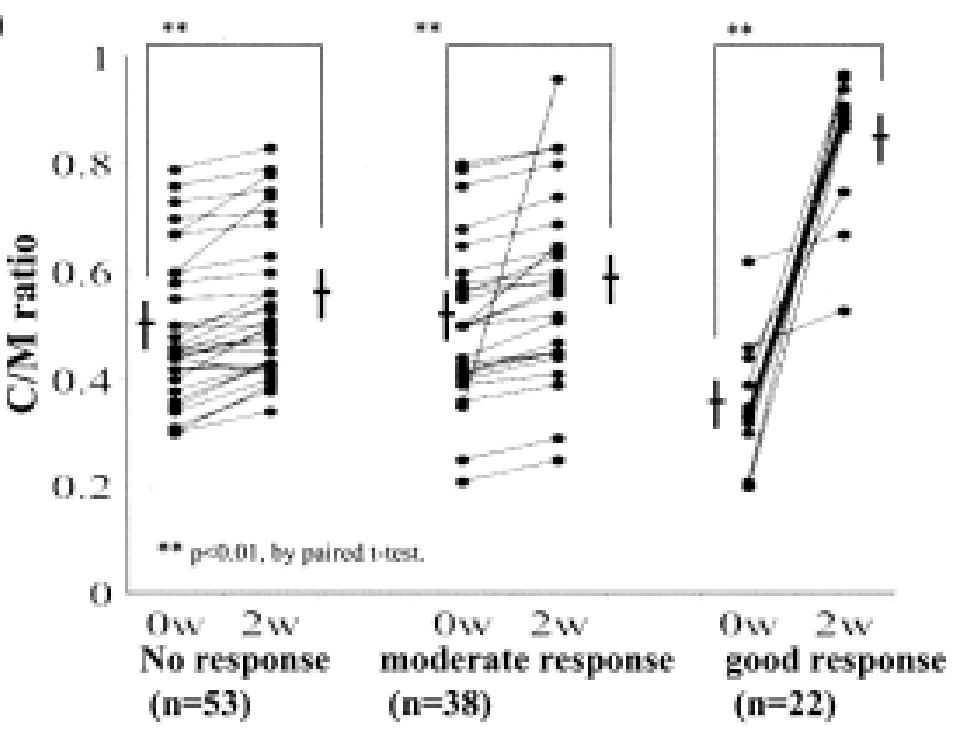

(d)

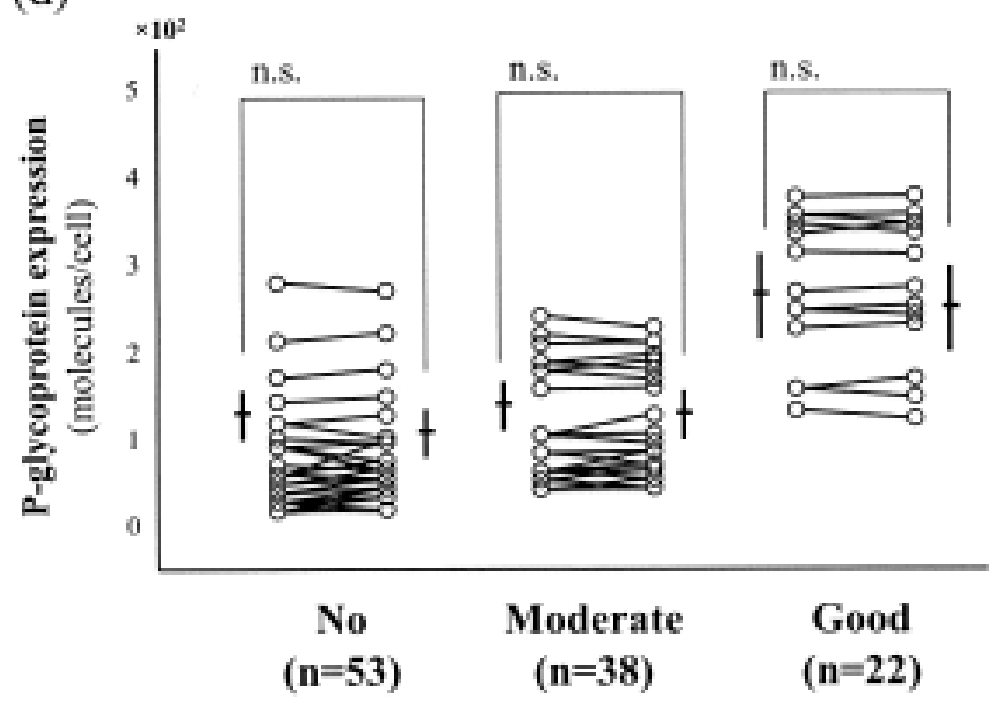

Figure 4. Continued.

Table 2. Multivariate logistic analysis of factors involved in response of patients with RA to tacrolimus treatment.

\begin{tabular}{lcccc}
\hline Measurement & Estimate & SE & Chi-square & Pr $>$ z \\
\hline Intercept & 0.1069 & 2.29120 & 0.00 & 0.9628 \\
C/M ratio & 9.0576 & 4.44129 & 4.16 & 0.0414 \\
P-glycoprotein expression & -0.0133 & 0.00609 & 4.79 & 0.0286 \\
$\quad$ on CD4+ lymphocyte & & & & \\
CRP & -0.1996 & 0.24054 & 0.69 & 0.4066 \\
MS & 0.00149 & 0.001593 & 0.88 & 0.3490
\end{tabular}

C/M: cell/medium; CRP: C-reactive protein; MS: morning stiffness. 


\section{REFERENCES}

1. Weyand CM. New insights into the pathogenesis of rheumatoid arthritis. Rheumatology 2000;39 Suppl 1:S3-8.

2. American College of Rheumatology Subcommittee on Rheumatoid Arthritis Guidelines. Guidelines for the management of rheumatoid arthritis: 2002 update. Arthritis Rheum 2002;46:328-46.

3. Tsujimura S, Saito K, Nakayamada S, Nakano K, Tanaka Y. Overcoming drug resistance induced by $\mathrm{P}$-glycoprotein on lymphocytes in patients with refractory rheumatoid arthritis. Ann Rheum Dis 2008;67:380-8.

4. Beck WT, Grogan TM, Willman CL, Cordon-Cardo C, Parham DM, Kuttesch JF, et al. Methods to detect P-glycoprotein-associated multidrug resistance in patients' tumors: consensus recommendations. Cancer Res 1996;56:3010-20.

5. Advani R, Visani G, Milligan D, Saba H, Tallman M, Rowe JM, et al. Treatment of poor prognosis AML patients using PSC833 (valspodar) plus mitoxantrone, etoposide, and cytarabine (PSC-MEC). Adv Exp Med Biol 1999;457:47-56.

6. List AF, Kopecky KJ, Willman CL, Head DR, Slovak ML, Douer $\mathrm{D}$, et al. Cyclosporine inhibition of P-glycoprotein in chronic myeloid leukemia blast phase. Blood 2002;100:1910-2.

7. Linn SC, Honkoop AH, Hoekman K, van der Valk P, Pinedo HM, Giaccone G. p53 and P-glycoprotein are often co-expressed and are associated with poor prognosis in breast cancer. Br J Cancer 1996;74:63-8.

8. Tsuruo T. Reversal of acquired resistance to vinca alkaloids and anthracycline antibiotics. Cancer Treat Rep 1983;67:889-94.

9. Tsujimura S, Saito K, Nakayamada S, Nakano K, Tsukada J, Kohno $\mathrm{K}$, et al. Transcriptional regulation of multidrug resistance-1 gene by interleukin-2 in lymphocytes. Genes Cells 2004;9:1265-73.

10. Shapiro R, Jordan ML, Scantlebury VP, Vivas C, Gritsch HA, Corry RJ, et al. The superiority of tacrolimus in renal transplant recipients - the Pittsburgh experience. Clin Transpl 1995:199-205.

11. Testa G, Klintmalm GB. Cyclosporine and tacrolimus: the mainstay of immunosuppressive therapy for solid organ transplantation. Clin Liver Dis 1997;1:417-37.

12. Kino T, Hatanaka H, Miyata S, Inamura N, Nishiyama M, Yajima T, et al. FK-506, a novel immunosuppressant isolated from a Streptomyces. II. Immunosuppressive effect of FK-506 in vitro. J Antibiot (Tokyo) 1987;40:1256-65.

13. Liu J, Farmer JD Jr, Lane WS, Friedman J, Weissman I, Schreiber SL. Calcineurin is a common target of cyclophilin-cyclosporin A and FKBP-FK506 complexes. Cell 1991;66:807-15.

14. Wiederrecht G, Lam E, Hung S, Martin M, Sigal N. The mechanism of action of FK-506 and cyclosporin A. Ann NY Acad Sci 1993;696:9-19.

15. Kelly PA, Burckart GJ, Venkataramanan R. Tacrolimus: a new immunosuppressive agent. Am J Health Syst Pharm 1995;52:1521-35.

16. Tsujimura S, Saito K, Nakayamada S, Nakano K, Tanaka Y. Clinical relevance of the expression of P-glycoprotein on peripheral blood lymphocytes to steroid resistance in patients with systemic lupus erythematosus. Arthritis Rheum 2005;52:1676-83.

17. Parasrampuria DA, Lantz MV, Benet LZ. A human lymphocyte based ex vivo assay to study the effect of drugs on P-glycoprotein (P-gp) function. Pharm Res 2001;18:39-44.

18. Saeki T, Ueda K, Tanigawara Y. Human P-glycoprotein transports cyclosporin A and FK506. J Biol Chem 1993;268:6077-80.

19. Yocum DE, Furst DE, Kaine JL, Baldassare AR, Stevenson JT, Borton MA, et al. Efficacy and safety of tacrolimus in patients with rheumatoid arthritis: a double-blind trial. Arthritis Rheum 2003;48:3328-37.

20. Yocum DE, Furst DE, Bensen WG, Burch FX, Borton MA, Mengle-Gaw LJ, et al. Safety of tacrolimus in patients with rheumatoid arthritis: long-term experience. Rheumatology 2004;43:992-9.

21. Kawai S, Hashimoto H, Kondo H, Murayama T, Kiuchi T, Abe T. Comparison of tacrolimus and mizoribine in a randomized, double-blind controlled study in patients with rheumatoid arthritis. J Rheumatol 2006;33:2153-61.

22. Kawai S, Yamamoto K. Safety of tacrolimus, an immunosuppressive agent, in the treatment of rheumatoid arthritis in elderly patients. Rheumatology 2006;45:441-4.

23. Kondo H, Abe T, Hashimoto H, Uchida S, Irimajiri S, Hara M, et al. Efficacy and safety of tacrolimus (FK506) in treatment of rheumatoid arthritis: a randomized, double blind, placebo controlled dose-finding study. J Rheumatol 2004;31:243-51.

24. Parasrampuria DA, Lantz MV, Benet LZ. A human lymphocyte based ex vivo assay to study the effect of drugs on P-glycoprotein (P-gp) function. Pharm Res 2001;18:39-44.

25. Saeki T, Ueda K, Tanigawara Y. Human P-glycoprotein transports cyclosporin A and FK506. J Biol Chem 1993;268:6077-80.

26. Arnett FC, Edworthy SM, Bloch DA, McShane DJ, Fries JF, Cooper NS, et al. The American Rheumatism Association 1987 revised criteria for the classification of rheumatoid arthritis. Arthritis Rheum 1988;31:315-24.

27. van der Heijde DM, van't Hof MA, van Riel PL, Theunisse LA, Lubberts EW, van Leeuwen MA, et al. Judging disease activity in clinical practice in rheumatoid arthritis: first step in the development of a disease activity score. Ann Rheum Dis 1990;49:916-20.

28. Prevoo ML, van't Hof MA, Kuper HH, van Leeuwen MA, van de Putte LB, van Riel PL. Modified disease activity scores that include twenty-eight-joint counts. Development and validation in a prospective longitudinal study of patients with rheumatoid arthritis. Arthritis Rheum 1995;38:44-8.

29. van Gestel AM, Prevoo ML, van't Hof MA, van Rijswijk MH, van de Putte LB, van Riel PL. Development and validation of the European League Against Rheumatism response criteria for rheumatoid arthritis. Comparison with the preliminary American College of Rheumatology and the World Health Organization/ International League Against Rheumatism Criteria. Arthritis Rheum 1996;39:34-40.

30. Villaverde V, Balsa A, Cantalejo M, Fernández-Prada M, Madero MR, Muñoz-Fernández S, et al. Activity indices in rheumatoid arthritis. J Rheumatol 2000;27:2576-81.

31. Balsa A, Carmona L, Gonzalez-Alvaro I, Belmonte MA, Tena X, Sanmarti R. Value of Disease Activity Score 28 (DAS28) and DAS28-3 compared to American College of Rheumatology-defined remission in rheumatoid arthritis. J Rheumatol 2004;31:40-6.

32. Tanaka Y, Minami Y, Mine S, Hirano H, Hu CD, Fujimoto H, et al. $\mathrm{H}$-Ras signals to cytoskeletal machinery in induction of integrin-mediated adhesion of T cells. J Immunol 1999;163:6209-16.

33. Tanaka Y, Wake A, Horgan KJ, Murakami S, Aso M, Saito K, et al. Distinct phenotype of leukemic T cells with various tissue tropisms. J Immunol 1997;158:3822-9.

34. Hamada H, Tsuruo T. Functional role for the 170 - to $180-\mathrm{kDa}$ glycoprotein specific to drug-resistant tumor cells as revealed by monoclonal antibodies. Proc Natl Acad Sci USA 1986;83:7785-9.

35. Tanaka Y, Minami Y, Mine S, Hirano H, Hu CD, Fujimoto H, et al. $\mathrm{H}$-Ras signals to cytoskeletal machinery in induction of integrin-mediated adhesion of T cells. J Immunol 1999;163:6209-16.

36. Richard C, John RR. Synthetic and natural opiates interact with P-glycoprotein in multidrug-resistant cells. J Biol Chem 1993;268:16059-64.

37. Frust DE. Acquired resistance of human T cell to sulfasalazine. Ann Rheum Dis 2004;63:115-6. 